Louisiana State University

LSU Digital Commons

Faculty Publications

Department of Biological Sciences

$9-1-2015$

\title{
The Human Shoulder Suspension Apparatus: A Causal \\ Explanation for Bilateral Asymmetry and a Fresh Look at the Evolution of Human Bipedality
}

Michelle L. Osborn

Louisiana State University

Dominique G. Homberger

Louisiana State University

Follow this and additional works at: https://digitalcommons.Isu.edu/biosci_pubs

\section{Recommended Citation}

Osborn, M., \& Homberger, D. (2015). The Human Shoulder Suspension Apparatus: A Causal Explanation for Bilateral Asymmetry and a Fresh Look at the Evolution of Human Bipedality. Anatomical Record, 298 (9), 1572-1588. https://doi.org/10.1002/ar.23178

This Article is brought to you for free and open access by the Department of Biological Sciences at LSU Digital Commons. It has been accepted for inclusion in Faculty Publications by an authorized administrator of LSU Digital Commons. For more information, please contact ir@lsu.edu. 


\title{
The Human Shoulder Suspension Apparatus: A Causal Explanation for Bilateral Asymmetry and a Fresh Look at the Evolution of Human Bipedality
}

\author{
MICHELLE L. OSBORN* AND DOMINIQUE G. HOMBERGER \\ ${ }^{1}$ Department of Biological Sciences, Louisiana State University, Baton Rouge, Louisiana
}

\begin{abstract}
The combination of large mastoid processes and clavicles is unique to humans, but the biomechanical and evolutionary significance of their special configuration is poorly understood. As part of the newly conceptualized shoulder suspension apparatus, the mastoid processes and clavicles are shaped by forces exerted by the musculo-fascial components of the cleidomastoid and clavotrapezius muscles as they suspend the shoulders from the head. Because both skeletal elements develop during infancy in tandem with the attainment of an upright posture, increased manual dexterity, and the capacity for walking, we hypothesized that the same forces would have shaped them as the shoulder suspension apparatus evolved in ancestral humans in tandem with an upright posture, increased manual dexterity, and bipedality with swinging arms. Because the shoulder suspension apparatus is subjected to asymmetrical forces from handedness, we predicted that its skeletal features would grow asymmetrically. We used this prediction to test our hypothesis in a natural experiment to correlate the size of the skeletal features with the forces exerted on them. We (1) measured biomechanically relevant bony features within the shoulder suspension apparatus in 101 male human specimens (62 of known handedness); and (2) modeled and analyzed the forces within the shoulder suspension apparatus from X-ray CT data. We identified eight right-handed characters and demonstrated the causal relationship between these right-handed characters and the magnitude and direction of forces acting on them. Our data suggest that the presence of the shoulder suspension apparatus in humans was a necessary precondition for human bipedality. Anat Rec, 298:1572-1588, 2015. (C) 2015 Wiley Periodicals, Inc.
\end{abstract}

Key words: mastoid process; clavicle; free-body diagram; sternocleidomastoid; trapezius; handedness; laterality; bipedality

\footnotetext{
Michelle L. Osborn is currently affiliated with Department of Pathology, College of Veterinary Medicine, The University of Georgia, 501 DW Brooks Drive, Athens, GA, 30602-7388.

Grant sponsor: Robert C. West Field Research Grant; LSU Foundation.

*Correspondence to: Michelle L. Osborn, Department of Pathology, College of Veterinary Medicine, The University of Georgia, Athens, GA. E-mail: mosborn@uga.edu
}

Received 29 June 2011; Revised 18 August 2014; Accepted 27 February 2015.

DOI 10.1002/ar.23178

Published online 5 June 2015 in Wiley Online Library (wileyonlinelibrary.com). 
The combination of large mastoid processes and clavicles is unique to humans among mammals. Although these two paired skeletal elements and their bony features have been analyzed in numerous anthropological and medical studies, the biomechanical and evolutionary significance of their special configuration has not attracted the attention it deserves.

The intimate structural and functional relationships among the head, neck, and shoulders prompted us to conceptualize these parts as a functional unit, the shoulder suspension apparatus, even though they are usually treated and analyzed separately (see, e.g., Kendall et al., 2005; Moore et al., 2010). In our conceptualization, the shoulders are suspended from the head by the fascial components of the multi-joint cleidomastoid muscle, which attaches to the mastoid process and to the clavicle, and the clavotrapezius muscle, which attaches to the superior nuchal line of the skull and to the clavicle, while the head and neck are stabilized by the core postural muscles of the cervical vertebral column. In a healthy and properly balanced upright posture, the musculo-fascial components of the shoulder suspension apparatus isometrically resist the forces created by the weight of the shoulders on the skull.

The phenomenon of muscle forces influencing the size, proportions, and physical properties of skeletal elements and their features is well-known (see, e.g., Wolff, 1892) and, although the precise mechanism of this influence is yet to be fully understood (Schlecht, 2012), recent studies continue to elucidate the relationship between mechanics and bone remodeling from the macroscopic to the cellular level (Bentley et al., 2007). And because the mastoid processes begin to acquire their distinctive size and shape postnatally (Cinamon, 2009), we hypothesized that the characteristic configuration of the human mastoid process and clavicle may at least partly be a function of the forces acting on them during postnatal development as an infant starts to sit up, stand up, and walk and, by extrapolation, during the evolution of a shoulder suspension apparatus as ancestral humans acquired an upright posture and bipedality. About 70$90 \%$ of humans use one hand preferentially, which results in bilateral asymmetries in the soft and bony tissues (see, e.g., Ruff, 2005; Steele and Mays, 2005; Sanchis-Moysi et al., 2012; Volpato et al., 2012; for additional references, see Osborn, 2013); like the size of the mastoid process, these asymmetries also increase during development (Murachovsky, 2010; Blackburn, 2011). Thus, our hypothesis is testable by ascertaining whether asymmetries in the forces that are naturally applied to the shoulder suspension apparatus are causally correlated with asymmetries of the bony features.

To test our hypothesis, we used (1) morphometry to analyze the degree of bilateral asymmetry of selected pairs of biomechanically relevant bony features; and (2) biomechanical modeling based on X-ray CT data to analyze and compute the forces applied to these features within the shoulder suspension apparatus.

\section{Materials}

\section{MATERIALS AND METHODS}

One hundred and one adult human skeletons from the William M. Bass Donated Skeletal Collection (University of Tennessee, Knoxville) were used for our morphometric study. Only males were measured because their muscle attachment sites tend to be more pronounced than those of females (see, e.g., Weiss, 2003; Fatah et al., 2012). The skeletons were from individuals who had lived during the 20th century. They had intact skulls, but 31 skeletons had incomplete postcranial elements, a fact discovered only after the skulls had already been measured (see below). Information regarding the handedness of the individuals was revealed only after all measurements had been analyzed and after the individuals' handedness had been predicted based on the biometric data. Of the 101 skeletons, 54 were right-handed, 8 were left-handed, and 39 were of unknown handedness.

Disarticulated bones from the Physical Anthropology Skeletal Teaching Collection (Dept. of Geography \& Anthropology, Louisiana State University) were used to estimate the measurement error and to set a benchmark by which to distinguish actual asymmetries from apparent asymmetries that may have been a result of measurement error.

X-ray CT data of the head, neck, shoulders, and upper thorax and arms of a human were obtained and used with permission from the National Library of Medicine's Visible Human Project ${ }^{\circledR}$ to create our biomechanical model. This individual was identified as right-handed on the basis of our research.

\section{Methods}

Measurement techniques. To ensure unbiased observations, measurements were taken in two rounds with the first round comprising all the skulls and the second round comprising all the postcranial bones. Measurement tools included a flexible tape measure and an osteometric board (both accurate to the nearest millimeter), and digital sliding calipers (accurate to the nearest micron). A piece of moist twine was used to measure the circumference of the mastoid process (for details, see Osborn, 2013).

Estimates of a benchmark to distinguish actual asymmetries from apparent asymmetries due to measurement error. We decided to set benchmarks to distinguish actual asymmetries from merely apparent asymmetries that are due to measurement error. As a first step, each bony feature was measured five times on the same bone on a given day and five times 2 weeks later for a total of ten measurements. We then compared two different approaches to estimating a benchmark. (1) We computed the standard deviation of each set of measurements. (2) We used the method outlined by White (2000): (a) We computed the mean of the ten measurements for each bony feature; (b) found the difference between the mean and each of the ten measurements; (c) ascertained the measurement error (in $\mathrm{mm}$ ) for each feature by dividing the sum of the ten differences by the number of measurements (ten); and (d) found the measurement error (in \%) by dividing the measurement error (in $\mathrm{mm}$ ) by the mean of the measurements and converting this value to a percent. We reported the measurement error (in \%) for each feature, but chose the standard deviation as a benchmark for asymmetry because it was more stringent. 


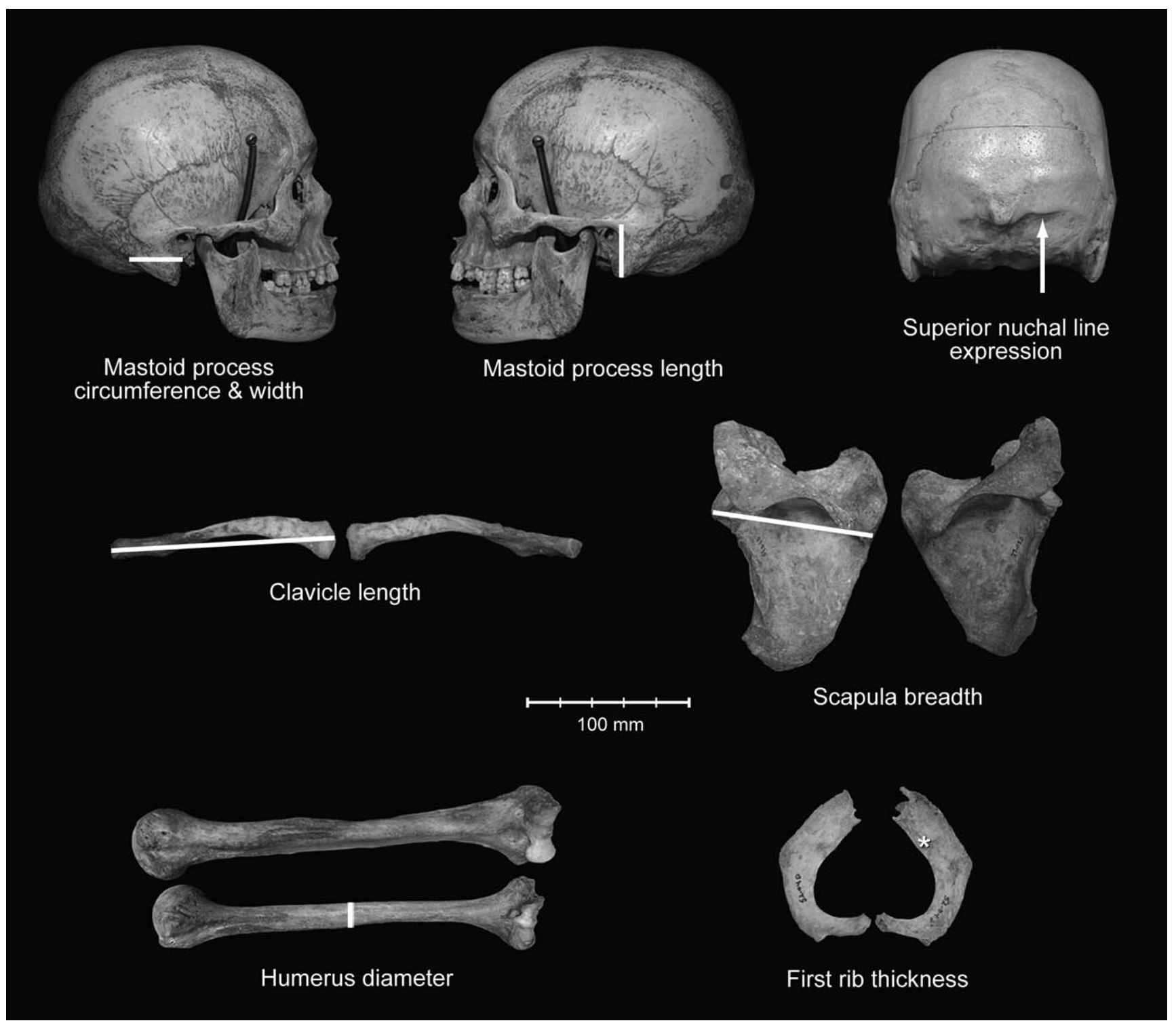

Fig. 1. Asymmetrical and biomechanically relevant paired bony features of the skeletal elements of the human shoulder suspension apparatus. Symbol: ${ }^{*}=$ location of the measurement of thickness in the vertical axis.

Analyzed bony features. Mastoid process. Circumference [Fig. 1; (for details, see Osborn, 2013)]: At the base of the mastoid process along the mastoid notch. Length (Fig. 1): From the top of the external auditory meatus to the mastoidale (i.e., the distal-most point of the mastoid process) (see, e.g., Moore-Jansen et al., 1994). Width (Fig. 1): From the postero-inferior ridge of the external auditory meatus to the posteriormost point of the mastoid process, where it meets the temporal bone.

Superior nuchal line. This qualitative feature was recorded in a subsample of 34 skeletons (19 righthanded, 3 left-handed, 12 of unknown handedness) because its asymmetry was noticed only after most skulls had already been measured. One side of the "m"shaped superior nuchal line often rises higher on the skull and/or is more pronounced and less curved than on the contralateral side (Fig. 1).

Clavicle. Diameter: At the level of the attachment site of the cleidomastoid muscle in the vertical axis. Circumference: At the level of the attachment site of the cleidomastoid muscle. Length (Fig. 1): From the medial end to the lateral end (see, e.g., Bass, 1995).

Scapula. Height: From the inferior to the superior angle of the scapula (see, e.g., Bass, 1995). Breadth (Fig. 1): From the midpoint of the inferior border of the glenoid fossa to the midpoint of the end of the spine of the scapula (see, e.g., Bass, 1995). Length of Spine: From the tip of the acromion to the midpoint of the medial border of the spine of the scapula (see, e.g., Bass, 1995).

Humerus. Diameter (Fig. 1): At mid-length (i.e., midshaft) (see e.g., Bass, 1995). 
First rib. Thickness (Fig. 1): At the level of the scalene tubercle in the vertical axis.

Data analysis. To ascertain differences between the right and left bony features (with a significance level of $\alpha \leq 0.05$ ), paired t tests (SPSS 17; SPSS, Chicago, IL) were applied to each pair of metric features in all individuals whose right and left features were present for measurement. The seven metric features that were significantly asymmetrical were used for further analysis and descriptive statistics. The means, ranges, and differences of the right and left sides of the significantly asymmetrical pairs of features were calculated with Excel (Microsoft Corporation, Redmond, WA). The right and left sides of the superior nuchal line were analyzed qualitatively.

Only those paired features that were above our benchmark for asymmetry (see above) were further analyzed.

To establish whether a suite of asymmetrical features was typical for right-handed individuals, we first identified whether the right or left side was larger for each paired feature. We then counted whether a feature was larger or smaller on the right side in the majority of individuals. Because roughly $65-90 \%$ of humans are right-handed (see Table 1), we assumed that the majority direction of asymmetry for a paired feature is indicative of right-handedness, thereby identifying it as a right-handed character. Conversely, we assumed that the minority direction of asymmetry indicated lefthandedness, thereby identifying it as a left-handed character.

To illustrate the degree of cohesion among features within individuals, we tabulated the direction of asymmetry of the paired features for each individual of known handedness.

We also evaluated the ability of individual righthanded characters to predict handedness by analyzing the individuals of known handedness with a chi-square test [R version 2.11.0 (Revolution Analytics, Palo Alto, CA)]. The $P$ value was based on 5,000 replications with a significance level of $\alpha \leq 0.05$.

Biomechanical model and analysis. Our biomechanical model was created by depicting the posterior view of the visualized x-ray CT data of the head, neck, shoulders, upper thorax, and arms of a human that was processed in Adobe Photoshop CS3 (Adobe Systems, San Jose, CA). The diagraming of the forces was executed in Adobe Illustrator CS3.

We used the method of free-body diagram force analysis (see, e.g., Dempster, 1961; Bock, 1974; Gans, 1974; Strother, 1977; Homberger, 1986) to analyze the forces in the model. This method is based on the premise that the various forces and torques (e.g., gravitational, loading and reaction forces) acting on a particular skeletal element balance one another in a state of static equilibrium and are resolved graphically as well as mathematically. The resulting analysis represents a static condition or an infinitesimally small instant within a movement (for details, see Osborn, 2013).

\section{RESULTS \\ Asymmetries of the Bony Features}

The measurement errors (in \%) for the eleven metric features that had been selected for their hypothesized biomechanical relevance were all below 12\% (Table 2). Eight of these features were statistically significantly asymmetrical (Table 3), but the scapular spine length was not considered further because almost none of the individuals passed our benchmark for asymmetry (Table 2). Thus, only seven metric asymmetrical features [i.e., mastoid process circumference, length and width; clavicle length; scapula breadth; humerus diameter; and first rib thickness (Fig. 1)] were used for further analysis.

The means and ranges of the right and left sides of the seven asymmetrical pairs of metric features demonstrate the large amount of variation in the size of the individual right and left features (Table 4) and the degree of asymmetry among the pairs of features (Table 5 ). The one qualitative feature, the superior nuchal line, was also asymmetrical (Figs. 1 and 2).

Each of these seven metric asymmetrical features had a measurement error below 4\% (Table 2). Individual measurements that fell below our benchmark for asymmetry (i.e., the standard deviation) (Table 2) were not used for further analysis and were recorded as such in our individual analysis (see below).

A polarity of asymmetry, which indicates whether the right or left side is larger, of the eight features was observed in a majority (59-79\%) of the total 101 measured individuals, whose handedness had not yet been revealed (Fig. 2A). For a subsample of 54 right-handed individuals, the polarity of asymmetry for the majority was considered to be a right-handed character, irrespective of whether the feature was larger or smaller on the right side (Fig. 2B), because the majority of a human population is right-handed (Table 1). Hence, the righthanded characters that were larger on the right side were the mastoid process circumference, mastoid process width, superior nuchal line expression, humerus diameter, and first rib thickness. The right-handed characters that were smaller on the right side were the mastoid process length, clavicle length, and scapula breadth. Contrary to expectation, the polarity of asymmetry for the subsample of eight left-handed individuals did not mirror that of the right-handed subsample (Fig. 2C). Thus, it was not possible to determine so-called lefthanded characters.

Right-handed individuals possessed right-handed characters, reverse right-handed characters (i.e., the opposite polarity from a right-handed character, such as a lesser diameter of the right humerus), and indeterminate features (i.e., asymmetries below our benchmark for asymmetry or missing data) in varying combinations (Tables 6 and 7). The majority of the individuals (33 out of 54, or $61 \%$ ) had four or more right-handed characters out of seven metric features (Table 6). Three pairs of individuals with five to seven right-handed characters (ID\# $70 \& 84$, $30 \& 43$, and $8 \& 74$ ) actually possessed the same combination of right-handed characters and indeterminate features (Table 6). Such commonalities of combinations were not observed in individuals with four or fewer righthanded characters. With the qualitative feature (i.e., the expression of the superior nuchal line) included, a slightly greater majority (12 out of 19 , or $63 \%$ ) had four or more 


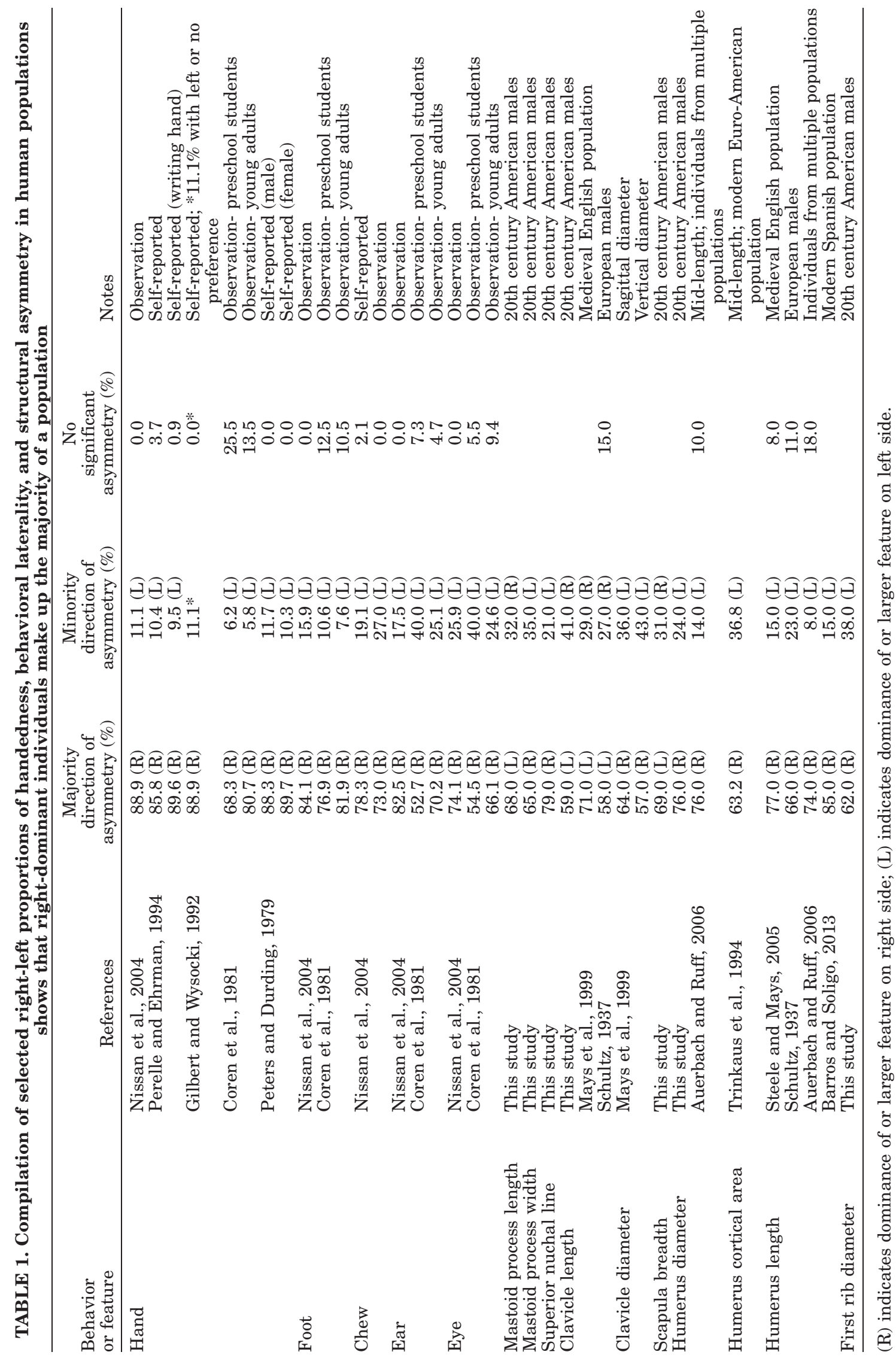


TABLE 2. Benchmarks for the difference between the right and left sides of paired features to distinguish actual asymmetry from apparent asymmetry due to possible measurement error

\begin{tabular}{|c|c|c|c|}
\hline \multirow[b]{2}{*}{ Measured features } & \multicolumn{2}{|c|}{$\begin{array}{c}\text { Benchmarks computed according to the method by } \\
\text { White (2000) }\end{array}$} & \multirow{2}{*}{$\begin{array}{c}\text { Benchmarks computed } \\
\text { according to the method } \\
\text { in this study } \\
\\
\text { Measurement } \\
\text { error (mm): } \\
\text { (standard deviation } \\
\text { of measurements) }\end{array}$} \\
\hline & $\begin{array}{l}\text { Measurement } \\
\text { error (\%): } \\
\text { (measurement } \\
\text { error in mm/mean } \\
\text { of measurements) }\end{array}$ & $\begin{array}{c}\text { Measurement } \\
\text { error (mm): } \\
\text { (sum of differences/number } \\
\text { of measurements) }\end{array}$ & \\
\hline Mastoid process circumference & 3.77 & 2.002 & 2.3 \\
\hline Mastoid process length & 2.62 & 0.802 & 1.1 \\
\hline Mastoid process width & 1.68 & 0.319 & 0.410 \\
\hline Clavicle diameter & 11.29 & 1.736 & 1.854 \\
\hline Clavicle circumference & 10.31 & 5.400 & 5.929 \\
\hline Clavicle length & 0 & 0 & 0 \\
\hline Scapula height & 0.22 & 0.340 & 0.516 \\
\hline Scapula breadth & 0.24 & 0.266 & 0.321 \\
\hline Scapular spine length & 6.11 & 9.800 & 10.426 \\
\hline Humerus diameter & 0.15 & 0.039 & 0.055 \\
\hline First rib thickness & 1.92 & 0.080 & 0.098 \\
\hline
\end{tabular}

TABLE 3. Paired samples $t$ test assesses the statistical significance of the difference between the right and left paired metric features in all individuals with a complete pair of features

\begin{tabular}{|c|c|c|c|c|c|}
\hline Paired features & $\begin{array}{c}\text { Mean difference } \\
(\mathrm{mm})\end{array}$ & $\begin{array}{c}\text { Standard } \\
\text { deviation }(\mathrm{mm})\end{array}$ & $t$ & $\mathrm{df}$ & $\begin{array}{l}\text { Significance } \\
\text { (two-tailed) }\end{array}$ \\
\hline Mastoid process circumference & -1.336 & 6.315 & -2.126 & 100 & .036 \\
\hline Mastoid process length & 1.038 & 2.497 & 4.178 & 100 & .000 \\
\hline Mastoid process width & -0.963 & 2.649 & -3.655 & 100 & .000 \\
\hline Clavicle diameter* & -0.247 & 1.863 & -1.281 & 92 & .203 \\
\hline Clavicle circumference* & 0.152 & 3.910 & 0.373 & 91 & .710 \\
\hline Clavicle length & 1.315 & 5.664 & 2.129 & 83 & .036 \\
\hline Scapula height* & -0.165 & 4.665 & -0.343 & 93 & .733 \\
\hline Scapula breadth & 0.760 & 2.058 & 3.599 & 94 & .001 \\
\hline Scapular spine length** & -2.811 & 4.213 & -6.502 & 94 & .000 \\
\hline Humerus diameter & -0.685 & 1.122 & -6.048 & 97 & .000 \\
\hline First rib thickness & -0.244 & 0.876 & -2.632 & 88 & .010 \\
\hline
\end{tabular}

Symbols: $*=$ features excluded from the final analysis because they did not reach statistical significance $(\leq 0.05)$;

$* *=$ feature excluded because almost none of the individuals passed the benchmark for asymmetry.

right-handed characters (Table 7). Of the 19 right-handed individuals in which the expression of the superior nuchal line was noted, none had fewer than three right-handed characters present, and none of them possessed the same combination of right-handed characters, reverse righthanded characters, and indeterminate features (Table 7).

Combinations of three or more right-handed characters were observed in varying degrees in right-handed individuals. For example, $31 \%$ of right-handed individuals (17 out of 54) possessed a combination of three righthanded characters with a greater mastoid process width, a lesser clavicle length, and a greater humerus diameter (Table 6), all of which were shown to be caused by known biomechanical forces (see Biomechanical Analysis). In contrast, a combination of three right-handed characters with a lesser clavicle length, lesser mastoid process length, and lesser right scapula breadth, the latter two of which are less well explained by our biomechanical model (see below), was observed in only $18.5 \%$ of right-handed individuals (10 out of 54) (Table 6). Although $22 \%$ of right-handed individuals (12 out of 54) possessed a combination of four right-handed characters with a greater mastoid process width, a lesser clavicle length, a lesser scapula breadth, and a greater humerus diameter, the addition of more characters to each combination generally resulted in fewer individuals that possessed those particular combinations of right-handed characters (Table 6).

Of all the right-handed characters, only the larger right humerus diameter can be used by itself to predict whether an individual is right-handed (Table 8).

\section{Biomechanical Analysis}

Our biomechanical model of a right-handed human in a relaxed and healthy upright posture (Fig. 3) reveals that the clavicles and shoulders are suspended from the skull by the fascial components of the multi-joint cleidomastoid and clavotrapezius muscles of the neck. Thus, the forces generated by the weight of the arms and shoulders are transmitted to the skull in equal magnitude but opposite direction. These forces will increase if the muscles contract either to move the shoulders or to 
maintain a balanced posture if additional weight is added to them.

The forces generated by the fascial components of the right muscles are greater than those of the left muscles even without any muscular contractions. Any additional weight on only one of the shoulders would require additional muscle forces to keep that shoulder level with the contralateral one. Any geometrical asymmetries of the skeleton, in turn, automatically require asymmetrical muscle forces to maintain balanced and level shoulders. For example, with the clavicle serving as a lever arm for the cleidomastoid and clavotrapezius muscles to lift and position the shoulder, the shorter lever arm of the shorter right clavicle requires a greater force of these two muscles on the right side than does the longer lever arm of the longer left clavicle (Fig. 3C,D).

Our model provides specific insights into the causality between asymmetrical forces and asymmetrical development of certain bony features. Hence, the greater weight of the right arm, as expressed morphometrically by the greater diameter of the right humerus (Fig. 2B), is resisted by a greater vertical force component of the fascial components of the right cleidomastoid and clavotrapezius muscles (Fig. 3C,D). At the same time, a greater muscle force would be needed to move or adjust the position of the right arm. Because muscles that habitually generate greater forces are also more developed, the right cleidomastoid muscle is better developed than the left one and, therefore, stimulates more bone growth at its attachments. This results in a wider right mastoid process with its greater circumference (Fig. 2B), which provides a larger surface area for the attachment of the thicker muscle (Fig. 3A,B). In turn, the more developed right clavotrapezius muscle stimulates more bone growth at the right superior nuchal line (Fig. 1), thereby providing a greater surface area for the attachment of its thicker musculo-fascial components (Fig. 3A,B).

The greater horizontal force component of the right clavotrapezius muscle (Fig. 3C,D) pushes the right clavicle against the equal and opposite horizontal force components of the right cleidomastoid muscle and the reaction force at the right sterno-clavicular joint (Fig. $3 \mathrm{C}, \mathrm{D})$, thereby restricting its lengthwise growth.

Using the comparison of the right and left clavicles as an example, our model also shows that individual variations in body proportions and muscle attachments automatically affect the proportions of the forces that are generated within the system. Because a shorter clavicle places the attachments sites of the cleidomastoid and clavotrapezius muscles closer to the center of rotation (i.e., the sternoclavicular joint), the forces generated by these muscles are greater for a shorter clavicle (e.g., the right clavicle in a right-handed individual) than for a longer one (e.g., the left clavicle in a right-handed individual) (Fig. 3C,D). Hence, in a right-handed individual, the right cleidomastoid and clavotrapezius muscles need to develop greater forces than the left ones and are, therefore, generally better developed. Furthermore, at a general level, an individual with shorter clavicles would need to have stronger muscles to lift a particular load than an individual with longer ones. In a comparable manner, the cleidomastoid and clavotrapezius muscles (and their respective forces) would be slightly reoriented in an individual with a longer neck and would thereby have a greater vertical force component relative 
to the horizontal one than an individual with a shorter neck and, therefore, would generate lesser compressive forces on the clavicle.

\section{DISCUSSION}

Our biomechanical model of the shoulder suspension apparatus in a right-handed individual incorporates our general morphometric data and makes explicit predictions about the functioning of its muscles, which can be tested by functional analytical methods (Homberger, 1986, 1988; Bock and Homberger, 1988), such as electromyography to test the predicted synchronization of contractions by different muscles (see, e.g., Basmajian, 1979; Loeb and Gans, 1986), strain gauges to test the predicted relative strains in different muscles and tendons (see, e.g., Herring et al., 2001), or piezoelectric crystals to test the predicted changes in the length of muscles and, thereby, of the distance between the skeletal elements to which they attach (see, e.g., Griffiths, 1991). It also corroborates the classic theories of Virchow (1858), Roux (1881), and Wolff (1892) concerning the influence of muscle forces on bone formation and supports recent observations that muscle forces influence the shape and size of bone (e.g., Krahl, 1976; Cowgill, 2007; Sládek et al., 2007; Auerbach and Raxter, 2008; Murachovsky et al., 2010; Preuschoft et al., 2010; Blackburn, 2011; Sanchis-Moysi et al., 2012; Wyland et al., 2012). More specifically, our model explains the causal interplay between greater musculo-fascial forces, better developed musculo-fascial components of particular muscles, and the size and shape of bony features serving as muscle attachments.

By comparing the bilateral asymmetries of the shoulder suspension apparatus of individuals of known handedness, our study also tests and supports the premise often used in physical anthropology studies that the features of the skeletal remains of an individual are evidence of his or her behavior during life (e.g., Stirland, 1993; Sládek et al., 2007; Volpato et al., 2012).

\section{The Effects of Right-handedness on Bony Features}

Our biomechanical model of the shoulder suspension apparatus of a right-handed individual in a relaxed and healthy upright posture shows that the forces generated by the fascial components of the right muscles are greater than those of the left even without muscular contractions. If these muscles contract either to move the right shoulder or to keep it balanced and at the same level with the left shoulder, the forces on the right side are even greater.

Our biomechanical analysis explains the causal relationship between greater musculo-fascial forces generated in the shoulder suspension apparatus and the greater or lesser expression of the following bony features that were identified as right-handed characters through our morphometric analysis: Mastoid process circumference, mastoid process width, clavicle length, and superior nuchal line expression. Among these right-hand characters, the clavicle is the only one that is shorter (i.e., lesser clavicle length) on the right side (see also Parsons, 1916; Mays et al., 1999; Fatah et al., 2012). Presumably, this is due to the fact that it is compressed 

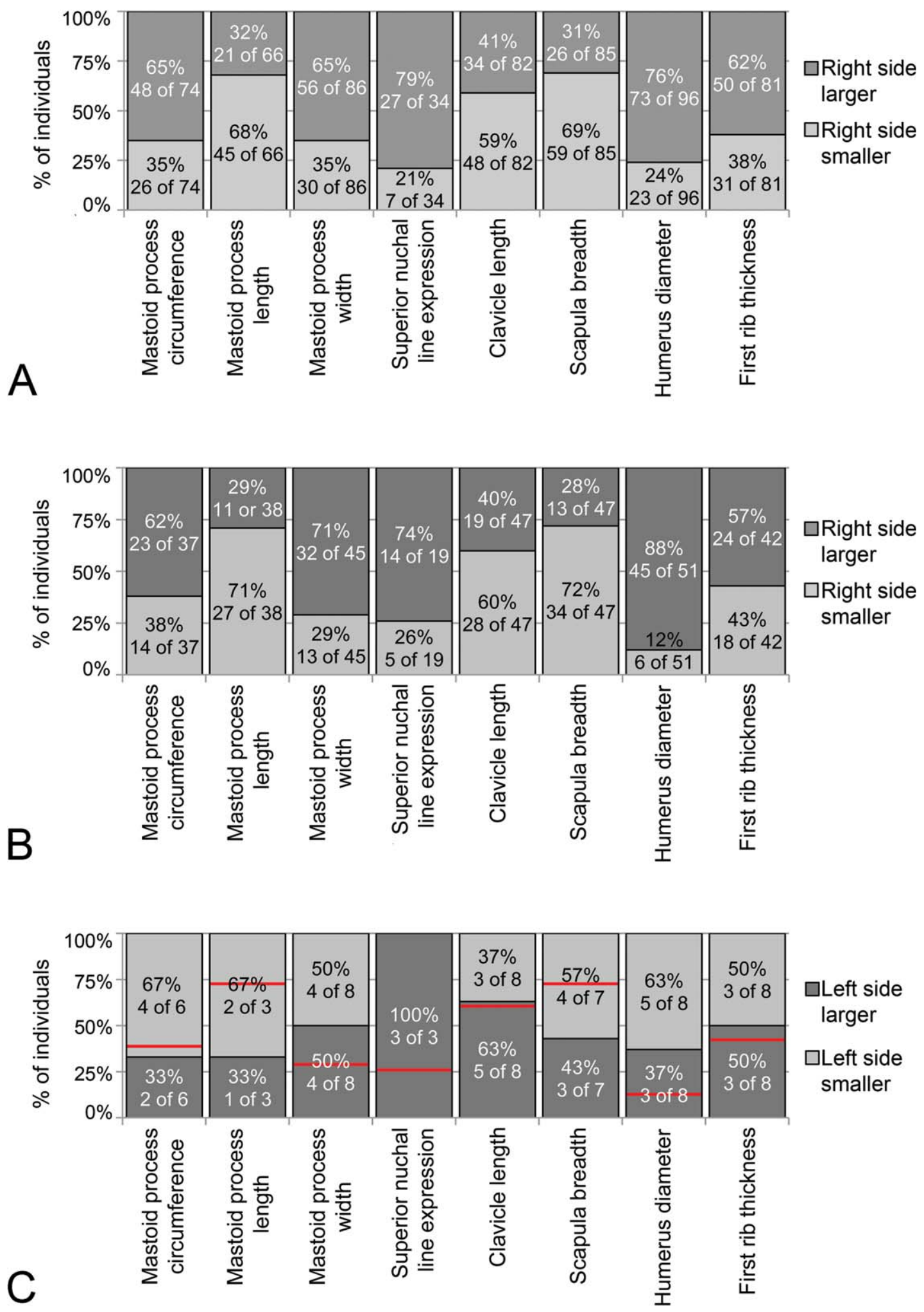

Fig. 2. Polarity of asymmetries of paired bony features of the skeletal elements of the human shoulder suspension apparatus. A: 101 individuals with undisclosed handedness. B: 54 right-handed individuals. C: 8 left-handed individuals; the red lines indicate the expected percentages if left-handed individuals were mirror-images of right-handed individuals. 
TABLE 6. Combinations of character states of the seven metric features for each of the 54 right-handed individuals

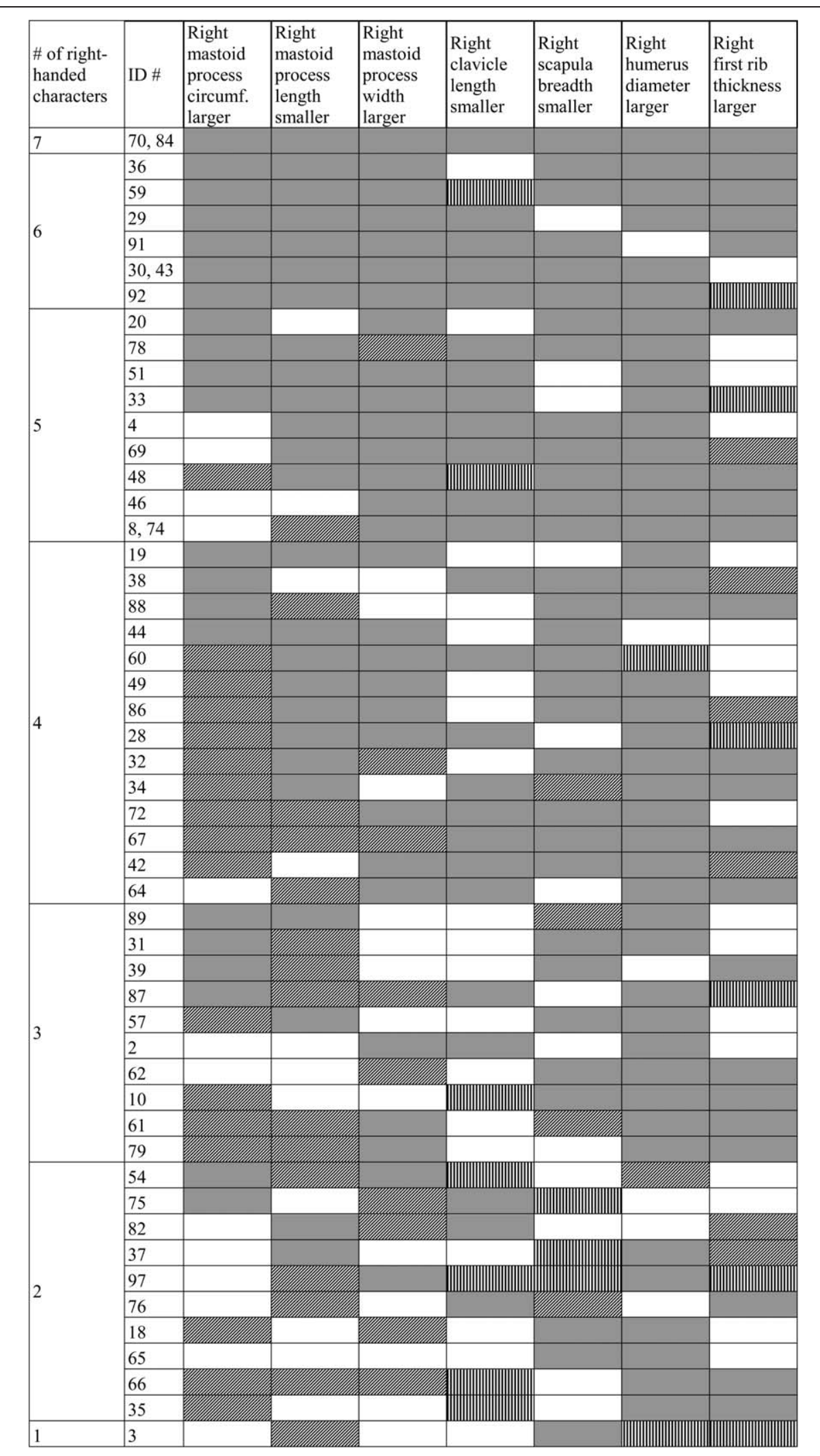

Box colors and patterns: grey = right-handed character; white = reverse right-handed character; diagonal stripes = asymmetry below the measurement error; vertical stripes $=$ missing data. 
TABLE 7. Combinations of various character states of the eight metric and qualitative features for each of the 19 right-handed individuals for whom data for the superior nuchal line were available

\begin{tabular}{|c|c|c|c|c|c|c|c|c|c|}
\hline $\begin{array}{l}\text { \# of right- } \\
\text { handed } \\
\text { characters }\end{array}$ & $\begin{array}{l}\text { ID } \\
\text { I }\end{array}$ & \begin{tabular}{|l|} 
Right \\
mastoid \\
process \\
circumf. \\
larger \\
\end{tabular} & \begin{tabular}{|l} 
Right \\
mastoid \\
process \\
length \\
smaller
\end{tabular} & \begin{tabular}{|l} 
Right \\
mastoid \\
process \\
width \\
larger \\
\end{tabular} & \begin{tabular}{|l|} 
Right \\
superior \\
nuchal line \\
expression \\
larger \\
\end{tabular} & $\begin{array}{l}\text { Right } \\
\text { clavicle } \\
\text { length } \\
\text { smaller }\end{array}$ & $\begin{array}{l}\text { Right } \\
\text { scapula } \\
\text { breadth } \\
\text { smaller }\end{array}$ & $\begin{array}{l}\text { Right } \\
\text { humerus } \\
\text { diameter } \\
\text { larger }\end{array}$ & $\begin{array}{l}\text { Right } \\
\text { first rib } \\
\text { thickness } \\
\text { larger }\end{array}$ \\
\hline \multirow{2}{*}{7} & 91 & & & & & & & & \\
\hline & 43 & & & & & & & & \\
\hline \multirow{3}{*}{6} & 20 & & & & & & & & \\
\hline & 69 & & & & & & & & \\
\hline & 48 & & & & & 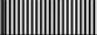 & & & \\
\hline \multirow{6}{*}{5} & 19 & & & & & & & & \\
\hline & 44 & & & & & & & & \\
\hline & 60 & & & & & & & & \\
\hline & 49 & & & & & & & & \\
\hline & 86 & & & & & & & & \\
\hline & 28 & & & & & & & & \\
\hline 4 & 34 & & & & & & & & \\
\hline \multirow{7}{*}{3} & 39 & & & & & & & & \\
\hline & 87 & & & & & & & & \\
\hline & 62 & & & & & & & & \\
\hline & 61 & & & & & & & & \\
\hline & 82 & & & & & & & & \\
\hline & 18 & & & & & & & & \\
\hline & 35 & & & & & & & & \\
\hline
\end{tabular}

Box colors and patterns: grey = right-handed character; white = reverse right-handed character; diagonal stripes $=$ asymmetry below the measurement error; vertical stripes = missing data.

between the larger medial force component of the right clavotrapezius muscle and the larger opposing lateral force components of the right cleidomastoid muscle and the reaction force at the right sterno-clavicular joint (Fig. 3C,D; see also Mays et al., 1999; Fatah et al., 2012). This finding also suggests that the entire clavicle may be enlarged (even in areas of no muscle attachment) to withstand these opposing forces, as was also posited by Fatah et al. (2012).

Other bony features that were also identified as righthanded characters through our morphometric analysis were less clearly explained by our biomechanical analysis. The right humerus tends to have a greater diameter (see also Auerbach and Ruff, 2006) presumably as a result of the stimulatory extra tension from the habitually more frequent and greater loads on the right arm in right-handed individuals. Although the measurement of the first rib was originally meant as a control measurement with the assumption that it would not be asymmetrical because it is not part of the shoulder suspension apparatus, it turned out that the scalene tubercle on the right first rib tends to be larger in righthanded individuals. This result is, however, not too surprising considering that the shoulder suspension apparatus indirectly also suspends the thorax via the clavicles and their attachments to the sternum through the sternomastoid and scalene muscles, and their articulations with the sternoclavicular joints. However, this aspect of the human shoulder suspension apparatus in its role as a thorax suspension apparatus requires a separate biomechanical analysis.
Two bony features that were identified as righthanded characters through our morphometric analysis could not be explained by our biomechanical analysis. First, the shorter right mastoid process as measured in this study is not correlated with any specific muscle force in our biomechanical model. This may be the result of our use of the standard measurement (see, e.g., Moore-Jansen et al., 1994) that includes the external auditory meatus which is, however, not part of the attachment site of the sternocleidomastoid muscle. In hindsight, Woo's (1931) measurement of the length of the mastoid process would have been more appropriate for our analysis because it parallels the fiber orientations and force directions of the sterno- and cleidomastoid muscles. Second, the lesser breadth of the right scapula may be related to greater balancing forces by the middle and lower trapezius muscle on the left side of right-handed individuals and would also explain the greater breadth of the left scapula. The complex muscle attachments on the scapula deserve and require a separate biomechanical analysis.

\section{Bilateral Asymmetry as a Natural Experiment}

Our analytical method uses the fact of human bilateral asymmetry due to handedness as a natural experiment to explore the effects of different force regimes on individual features. It controls variables (e.g., differences in genetic background, epigenetics, behavior, environmental influences, etc.) that cannot be controlled in a sample of skeletal specimens, by comparing the left and 
TABLE 8. Chi-square test assesses the ability of individual metric right-handed characters to differentiate between right- and left-handed individuals

\begin{tabular}{|c|c|c|c|c|c|}
\hline Feature & Polarity & $\begin{array}{l}\text { \# of right-handed } \\
\text { individuals with } \\
\text { polarity of feature }\end{array}$ & $\begin{array}{l}\text { \# of left-handed } \\
\text { individuals with } \\
\text { polarity of feature }\end{array}$ & $X^{2}$ value & Significance \\
\hline \multirow{2}{*}{$\begin{array}{l}\text { Right mastoid process } \\
\text { circumference }\end{array}$} & Larger & 23 & 02 & 1.763 & 0.3711 \\
\hline & Smaller & 14 & 04 & & \\
\hline \multirow[t]{2}{*}{ Right mastoid process length } & Larger & 11 & 01 & 0.0258 & 1.0 \\
\hline & Smaller & 27 & 02 & & \\
\hline \multirow[t]{2}{*}{ Right mastoid process width } & Larger & 32 & 04 & 1.3895 & 0.4019 \\
\hline & Smaller & 13 & 04 & & \\
\hline \multirow[t]{2}{*}{ Right clavicle length } & Larger & 19 & 05 & 1.3544 & 0.2841 \\
\hline & Smaller & 28 & 03 & & \\
\hline \multirow[t]{2}{*}{ Right scapula breadth } & Larger & 13 & 03 & 0.6749 & 0.6545 \\
\hline & Smaller & 34 & 04 & & \\
\hline \multirow[t]{2}{*}{ Right humerus diameter } & Larger & 45 & 03 & 11.7354 & 0.0034 \\
\hline & Smaller & 06 & 05 & & \\
\hline \multirow[t]{2}{*}{ Right first rib thickness } & Larger & 24 & 03 & 0.1088 & 1.0 \\
\hline & Smaller & 18 & 03 & & \\
\hline
\end{tabular}

A significance less than, or equal to, $0.05(\alpha \leq 0.05)$ indicates a statistically significant probability for a character to do so.

right features of the same individual. The causes for any differences between the left and right features can then be attributed to the preferential use of one side and explained through a biomechanical analysis. For this method to provide a causal explanation, however, the biometrical data need to be kept together for each individual.

\section{Analysis of Functionally Coherent and Integrated Complex Systems}

Our analytical method maintains the inherent structural integrity of the shoulder suspension apparatus because it focuses on the combined features of each individual and their interdependent functions. The functional coherence of the shoulder suspension apparatus cannot be fully understood by treating morphometrical data only with a standard statistical analysis, such as descriptive statistics, paired t-tests, and chi-square tests because these standard statistical tests destroy the coherence of the measurements in an individual by combining these quantities into an "average" individual, which does not exist in reality. In reality, elements of an integrated apparatus are mutually adjusted to form a biomechanically and functionally coherent system. Such systems vary among individuals with different body proportions and muscle attachments, but remain functionally coherent as long as their constituent elements covary [see also Cuvier's "Principle of the Correlation of Parts" (McBirney and Cook, 2009)]. This means that any standard statistical tests need to be supplemented by an analysis, such as ours, that retains the functional coherence of the features of an apparatus of each individual. Other studies have also remarked on the need for population-level analyses to be supplemented by analyses at the individual level (e.g., Rhodes, 2006; Barros and Soligo, 2013).

Biomechanically and individually coherent data are especially useful and relevant for evolutionary studies, because evolutionary change is driven by individual variation and because selective regimes involve whole organisms and not simply their individual parts.

\section{Right-handed Versus Left-handed Characters}

Not surprisingly in hindsight, our initial expectation that right-handed individuals would possess only righthanded characters was not fulfilled. Although two of the right-handed individuals (ca. 4\%) actually possessed a full suite of morphometric right-handed characters, the majority of right-handed individuals possessed varying combinations of right-handed characters, reverse righthanded characters, and indeterminate features in different proportions. The variability in composition of bilateral asymmetries within an individual and between individuals that is shown in our study suggests that the biomechanical causes of asymmetries are complex, affecting each bony feature in each individual in a different way (Auerbach and Ruff, 2006; Barros and Soligo, 2013; Cashmore and Zakrzewski, 2013). This variability is likely due to a variety of underlying causes, such as idiosyncratic behaviors, occupations that require habitual postures (e.g., the stoop of a dentist or the forward head posture of a data entry specialist or microscopist) or repetitive movements (e.g., the throwing of baseballs by a pitcher or the throwing of pots by a ceramicist; (see also Pieper, 1998; Murachovsky et al., 2010; Wyland, 2012), besides variations in the morphology and location of muscle attachments due to genetic and epigenetic causes.

Our observation that left-handed individuals are not simply mirror images of right-handed individuals in terms of asymmetrical characters (see also LeMay, 1977) is also not surprising given that left-handed individuals must function in a world that has been adapted to the majority population of right-handed people, but an analysis based on a larger sample size of left-handed individuals is needed for a better understanding of their bilateral asymmetry.

A sample of left-handed individuals that is comparable to that of right-handed individuals may also allow our morphometric data to be used in forensic cases. It appears that a combination of four or more right-handed characters in an individual may be suggestive of righthandedness because none of the eight left-handed individuals had more than three right-handed characters, 
but this will need to be corroborated by a larger sample of left-handed individuals.

\section{Analogy Between the Postnatal and Evolutionary Developments of the Human Mastoid Process and Clavicle}

Changes within the head, neck, and shoulders, which must have occurred during the evolution of bipedal humans from quadrupedal ancestors, are gradual macroevolutionary transformations that cannot be directly observed in real time. Instead, they must be reconstructed from indirect evidence provided by functional and comparative anatomy. Our demonstration that the size of skeletal features of the shoulder suspension apparatus is causally related to mechanical forces also explains why the mastoid processes and clavicles acquire their definitive shape in humans only postnatally when infants develop manual dexterity while learning to sit upright and, eventually, learning to walk (i.e., as they obtain a shoulder suspension apparatus). Thus, during this time period, the force regime applied to the head, neck, and shoulders changes while an infant develops from an essentially quadrupedal form of locomotion to a bipedal one. A similar change of the force regime can be inferred for the macroevolutionary transformation of the postural and locomotory configurations of the head, neck, and shoulders in a quadruped mammal to that of a bipedal human (Osborn, 2013).

\section{The Role of the Shoulder Suspension Apparatus in the Evolution of Human Bipedality}

Given the uniqueness of the human shoulder suspension apparatus among primates, the question of its selective advantage arises, especially because both of its defining features probably have had a negative selective value in human evolution, such as (1) potentially lethal complications from secondary infections of the internal air cells of an enlarged mastoid process as a consequence of middle ear infections (for a review of the particular pathology, see Ginsburg et al., 1980; Luntz et al., 2001; Bauer et al., 2002); (2) potential obstetric complications during parturition due to the elongated clavicles and broadened shoulders having to pass through a narrow birth canal (for a review of the particular pathology, see Trevathan, 1988); and (3) potential impairment of the use of the arms and hands due to a compression of the brachial plexus between the clavicle and first rib (for a review of the particular pathology, see Al Hadi et al., 2001; Moore et al., 2010) (see Fig. 4). Hence, for the shoulder suspension apparatus with its enlarged mastoid processes and clavicles to have evolved in humans it must have had a significantly positive selective value that overrode its negative aspects. To understand the evolutionary origin of the human shoulder suspension apparatus, it is necessary to reconstruct the selective regime that promoted it over the existing head, neck and shoulder construction of non-human primates; we posit that its selective value was derived from its role in supporting manual dexterity in a seated upright posture and as a prerequisite for and a role in human bipedality.

A large mastoid process has previously been related to an upright posture in humans (e.g., Hooton, 1946; Krantz, 1963; Tobias, 1992) and to the upright sitting behavior in Gelada baboons (Theropithecus gelada) (Jolly, 1970). An upright posture, in turn, has previously been hypothesized as a precondition for manipulating or carrying objects with both hands (see Videan and McGrew, 2002; Preuschoft, 2004; Carvalho et al., 2012). Although many non-human primates assume a sitting position when manipulating objects (Jolly, 1970; Rose, 1976), they lack the combination of distinct mastoid processes and clavicles and, therefore, do not have a human-type shoulder suspension apparatus. Our analysis provides new data that explain the biomechanical causes for the evolution of large mastoid processes and clavicles as a consequence of an upright posture. It also explains how the suspension apparatus is necessary in stabilizing and moving the shoulders so that both arms and hands are free to manipulate objects. The selective advantage of the human shoulder suspension apparatus over the ancestral head, neck and shoulder construction of non-human primates is unclear and will require a comparative biomechanical analysis to be understood. We can, however, surmise that during the evolution of the shoulder suspension apparatus, the forces of the sternocleidomastoid and clavotrapezius muscles were reoriented, thereby modifying the growth, shape, and size of the muscle attachment sites in a similar manner as the muscle forces are reoriented during infancy with the capacity to sit upright and to walk erect with swinging arms (e.g., Keen, 1993; Ledebt, 2000) and a concomitant growth of the mastoid processes.

The shoulder suspension apparatus is likely to have been a precondition for the evolution of human bipedality. Non-human primates walk bipedally only occasionally and only for short distances with wide stances with bent knees and trunk (see Rose, 1976; Doran, 1993; Videan and McGrew, 2002; D'Août et al., 2004; Carvalho et al., 2012). Humans, in contrast, walk bipedally for long distances with their trunk erect, their head vertically aligned with their body's center of gravity above their feet, and their arms swinging back-and-forth. These back-and-forth oscillations of the shoulders and arms are synchronized with the back-and-forth oscillations of the legs; they contribute towards maintaining a dynamic equilibrium and an efficient bipedal locomotion (Preuschoft and Witte, 1991; Pontzer et al., 2009; Bruijn et al., 2010; Stephenson et al., 2010; Meyns et al., 2013; Arellano and Kram, 2014). The swinging of the arms is facilitated by the elongated lumbar vertebral column and barrel-shaped thorax, which are characteristic for humans (see Ward, 2002; Preuschoft, 2004; Schmid et al., 2013), as well as by the lateral positioning of the clavicles, which broaden the shoulders and move them away from the thorax. Although the large and backward-curving clavicles in humans enable the erect body alignment necessary for human bipedality (Tobias, 1992), we suggest that this re-alignment had to be combined with a shoulder suspension apparatus, which allows the arms to hang down and swing freely backand-forth, in order for the evolutionary path towards human bipedality to be opened.

In addition, the shoulder suspension apparatus enables the shoulders to twist around the thorax independently from the head. This mobility, in turn, allows the head to rotate independently from the shoulders in order to scan the environment despite the restricted field of vision of humans. During walking, (1) the hips and the 

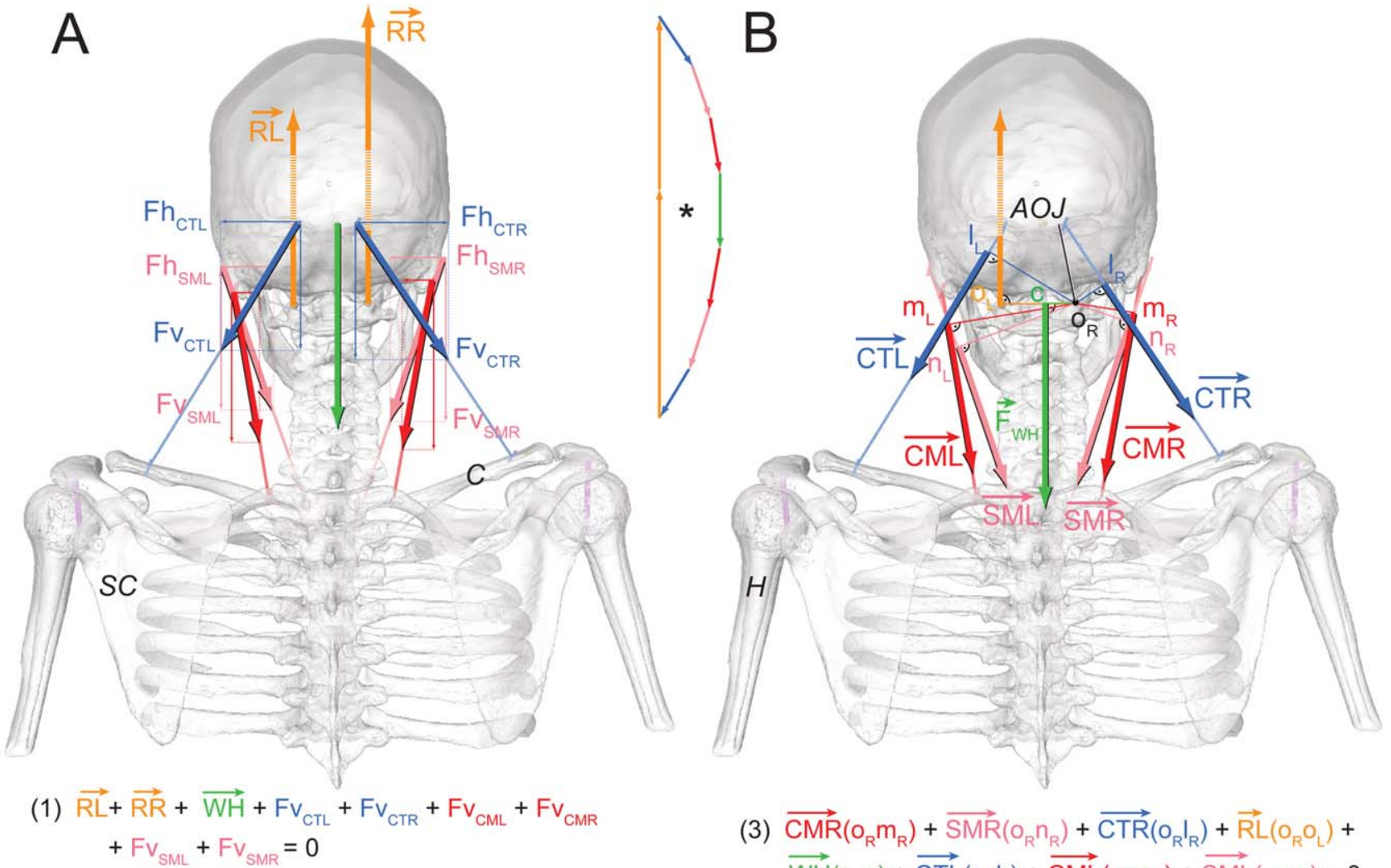

(2) $\mathrm{Fh}_{\mathrm{CTL}}+\mathrm{Fh}_{\mathrm{CTR}}+\mathrm{Fh}_{\mathrm{CML}}+\mathrm{Fh}_{\mathrm{CMR}}+\mathrm{Fh}_{\mathrm{SML}}+\mathrm{Fh}_{\mathrm{SMR}}=0$

(3) $\overrightarrow{C M R}\left(o_{R} m_{R}\right)+\overrightarrow{S M R}\left(o_{R} n_{R}\right)+\overrightarrow{C T R}\left(o_{R} I_{R}\right)+\overrightarrow{R L}\left(o_{R} O_{1}\right)+$ $\overrightarrow{W H}\left(O_{R} c\right)+\overrightarrow{C T L}\left(o_{R} I_{L}\right)+\overrightarrow{C M L}\left(o_{R} m_{L}\right)+\overrightarrow{S M L}\left(o_{R} n_{L}\right)=0$

(4) $\overrightarrow{C M}=\overrightarrow{S M}$
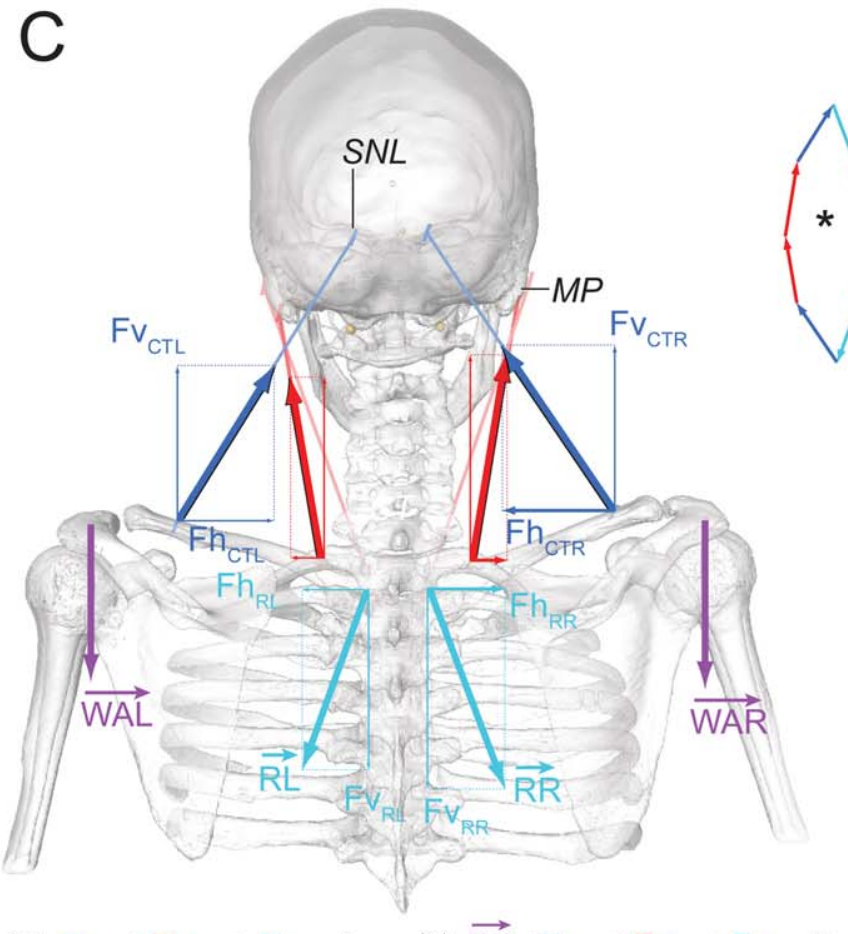

(5) $\mathrm{Fh}_{\mathrm{CT}}+\mathrm{Fh}_{\mathrm{CM}}+\mathrm{Fh}_{\mathrm{R}}=0$

(6) $\overrightarrow{W A}+F v_{C T}+F v_{C M}+F v_{R}=0$

D

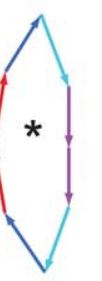

Fig. 3. Free-body force diagrams of the skeletal elements of the human shoulder suspension apparatus in a posterior view of a righthanded female human skeleton (used with permission from the National Library of Medicine's Visible Human Project ${ }^{\circledR}$ ) to demonstrate the asymmetrical forces acting on them. A: Analysis of forces acting on the skull. B: Analysis of torques acting on the right atlanto-occipital joint as the center of rotation. The analogous torques acting on the left atlanto-occipital joint as the center of rotation are not shown in order not to overcomplicate the image. C: Analysis of forces acting on both clavicles. D: Analysis of torques acting on both clavicles. Abbreviations: $\mathrm{AOJ}=$ atlanto-occipital joint; $\mathrm{C}=$ clavicle; $\mathrm{CML}=$ left cleido-

mastoid muscle; $\quad \mathrm{CMR}=$ right cleidomastoid muscle; $\mathrm{CTL}=$ left clavotrapezius muscle; CTR = right clavotrapezius muscle; CV = cervical vertebrae; $\mathrm{F}=$ resultant force; $\mathrm{Fh}=$ horizontal force component; $\mathrm{Fv}=$ vertical force component; $\mathrm{H}=$ humerus; $\mathrm{MP}=$ mastoid process; $\mathrm{O}=$ center of rotation; $\mathrm{RL}=$ left reaction force; $\mathrm{RR}=$ right reaction force; SC = scapula; SCJ = sterno-clavicular joint; SML= left sternomastoid muscle; SMR = right sternomastoid muscle; $\mathrm{SNL}=$ superior nuchal line; ST = sternum; WAL $=$ weight of left arm; WAR $=$ weight of right arm; $\mathrm{WH}=$ weight of head. Symbol: * = closed figures of the balanced resultant and reaction forces, scaled to fit in the given space. 


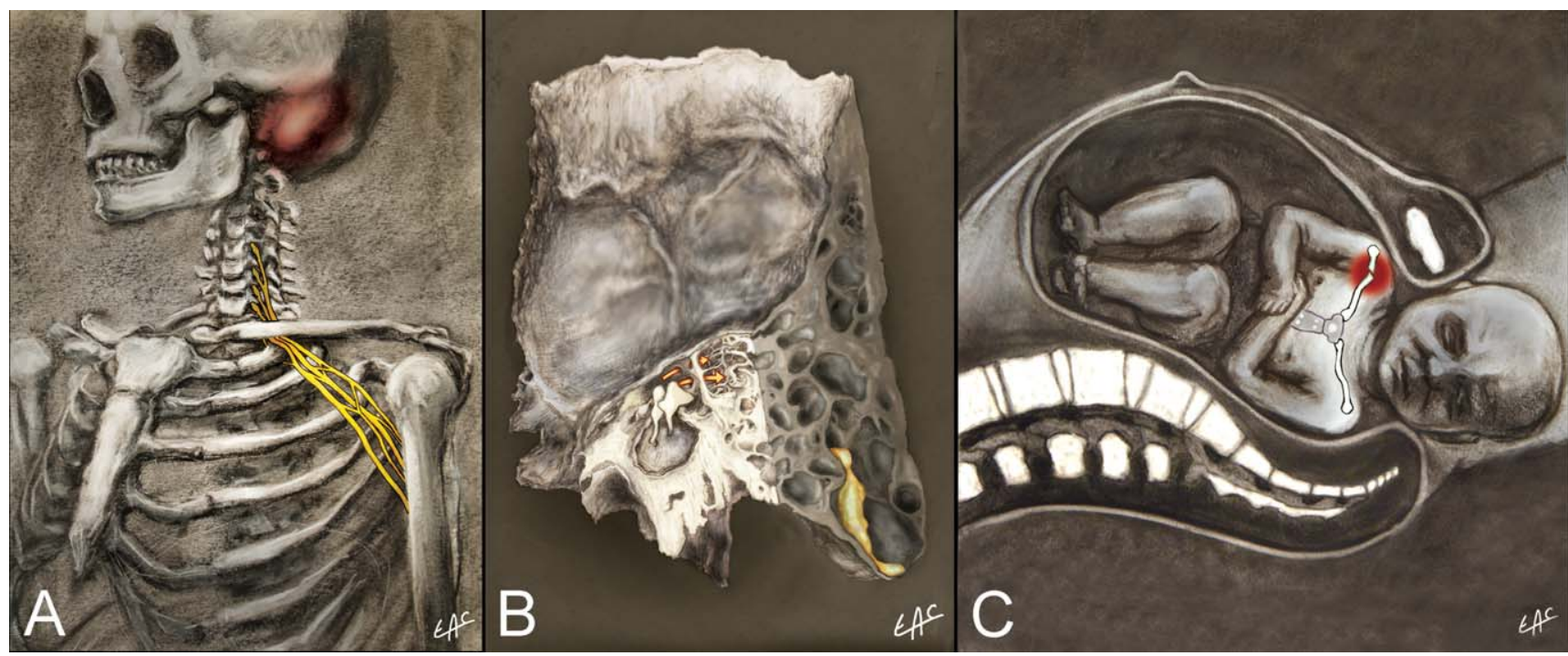

Fig. 4. The human mastoid process and clavicle as liabilities with life-threatening potential. A: Inflammation of the mastoid process and compression of nerves of the brachial plexus between the clavicle and first rib. B: Infected air cells of the mastoid process as a consequence of Otitis media. C: Wedged shoulders and broken clavicle potentially damage nerves of the brachial plexus during birth. (Illustrations by Elizabeth A. Cook).

sacrum rotate with the swing leg as it moves forward, (2) the trunk (lumbar and thoracic vertebrae) twists in the opposite direction (Lovejoy, 1988; Callaghan et al., 1999; Dedieu and Zanone, 2012), and (3) the shoulder girdle twists in the opposite direction to that of the trunk (Dedieu and Zanone, 2012), thereby moving forward the shoulder and arm opposite the swing leg. At the same time, the head generally remains oriented forward to retain a sense of direction and equilibrium (see also Pozzo et al., 1995; Michaelson et al., 2003). Experiments by Pontzer et al. (2009) test and support our interpretation of the biological role and selective value of the shoulder suspension apparatus for the evolution of bipedality in humans. When humans walk with their arms folded in front of them, their trunk, shoulders and head rotate together (Pontzer et al., 2009); we surmise that in this case the head would have to rotate sharply in the opposite direction to remain facing forward, but would not make this awkward movement in this experimental situation, just as humans do not freely walk in this manner. When humans walk with freely swinging arms, the extent of trunk and head rotations are reduced in comparison to those in the experimental condition (Pontzer et al., 2009); we surmise that in this case the shoulder girdle can rotate relative to the trunk and, thereby, frees the neck and head to move only slightly to face the direction of forward movement.

Finally, the evolution of the shoulder suspension apparatus also enabled humans to undertake long-distance walks while carrying loads, such as infants, weapons, and tools. This unique capacity undoubtedly facilitated the migration of humans out of Africa and expansion into a great variety of new environments and their successful competition with the autochthonous fauna. Nonhuman primates carrying loads (e.g., food) walk bipedally only occasionally and for short distances, or tripedally while holding loads with one hand close to their forward-bent trunk (see Rose, 1976; Doran, 1993; Videan and McGrew, 2002; D'Août et al., 2004; Carvalho et al., 2012). Humans, in contrast, can walk while carrying loads in containers in their hands hanging down from their shoulders or placed on their shoulders on poles or in backpacks. The shoulder suspension apparatus, by being able to counteract additional weight placed on the shoulders, allows for this behavioral innovation.

\section{ACKNOWLEDGEMENTS}

The specimens used for our study were made available by Dr. Lee Meadows-Jantz and Dr. Joseph T. Hefner (William M. Bass Donated Skeletal Collection, Dept. of Anthropology, University of Tennessee, Knoxville), Dr. Robert G. Tague (Physical Anthropology Teaching Collection, Dept. of Geography \& Anthropology, LSU), and Dr. William J. Swartz (Dept. of Cell Biology \& Anatomy, LSU Health Sciences Center, New Orleans). Space for our anatomical studies at the LSU School of Veterinary Medicine was provided by Dr. Daniel J. Hillmann, Dr. Hermann H. Bragulla, and Dr. Ray Wilhite. Statistical expertise was provided by Dr. Robert G. Tague, Dr. Michael Leitner, Dr. Bin Li, Michael G. McKenna, Shaofeng Pei, and Blake Perez. Expertise in combinatorics was provided by Dr. Thomas C. Redd and Dr. Jeffrey W. Roland. Expertise with the free-body diagram force analysis was provided by Dr. A. Ravi P. Rau. Discussions and feedback on various aspects of our research were provided by Dr. William J. Swartz, Dr. Keith P. Melancon, Dr. Robert G. Tague, Dr. Miles E. Richardson, Patricia A. O'Neill, Lorrain Doucet, Bernitta Berniard, Jonathan S. Garrett, and Dr. Kurt A. LeJeune. Valuable comments on early versions of the manuscript were provided by Dr. Pierre Legreneur, Professor Dr. Holger Preuschoft, Dr. Jeffrey T. Laitman, and three anonymous reviewers. Technical assistance was provided by Sigrid 
N. Hamilton, Elizabeth A. Cook, Dr. Brooke H. Dubansky, Jonathan A. Bonin, Bradley M. Wood, Roy J. Andermann, and Elise R. Orellana. Housing in Knoxville was graciously provided to MLO by Dr. Natalie Shirley. Travel awards to MLO were provided by the American Association of Anatomists (AAA), the Society for Integrative \& Comparative Biology (SICB), the LSU Graduate School, and the LSU Biological Graduate Student Association.

\section{LITERATURE CITED}

Al HM, Geary M, Byrne P, McKenna P. 2001. Shoulder dystocia: risk factors and maternal and perinatal outcomes. J Obstet Gynaecol 21:332-334.

Arellano CJ, Kram R. 2014. The metabolic cost of human running: is swinging the arms worth it? J Exp Biol 217:2456-2461.

Auerbach BM, Ruff CB. 2006. Limb bone bilateral asymmetry: variability and commonality among modern humans. J Hum Evol 50:203-218.

Auerbach BM, Raxter MH. 2008. Patterns of clavicular bilateral asymmetry in relation to the humerus: variation among humans. J Hum Evol 54:663-674.

Barros A, Soligo C. 2013. Bilateral asymmetry of humeral torsion and length in African apes and humans. Folia Primatol 84:220 238.

Basmajian JV. 1979. Muscles alive. 4th ed. Baltimore, MD: Williams and Wilkins.

Bass WM. 1995. Human osteology: a laboratory and field manual 4th ed. Columbia, MO: Missouri Archaeological Society.

Bauer PW, Brown KR, Jones DT. 2002. Mastoid subperiosteal abscess management in children. Int J Pediatr Otorhi 63:185188.

Bentley VA, Sample SJ, Livesey MA, Scollay MC, Radtke CL, Frank JD, Kalscheur VL, Muir P. 2007. Morphologic changes associated with functional adaptation of the navicular bone of horses. J Anat 211:662-672.

Blackburn A. 2011. Bilateral asymmetry of the humerus during growth and development. Am J Phys Anthropol 145:639-646.

Bock WJ. 1974. The avian skeletomuscular system. In: Farner DS, King JR, Parkes KC, editors. Avian biology. Vol. II. New York, NY: Academic Press. p 119-257.

Bock WJ, Homberger DG. 1988. Preface to the symposium: questions, explanations, models and tests in morphology: the interaction between hypotheses and empirical observations. Am Zool 28:185-187.

Bruijn SM, Meijer OG, Beek PJ, van Dieën JH. 2010. The effects of arm swing on human gait stability. J Exp Biol 213:3945-3952.

Callaghan JP, Patla AE, McGill SM. 1999. Low back pain threedimensional joint forces, kinematics, and kinetics during walking. Clin Biomech 14:203-206.

Carvalho S, Biro D, Cunha E, Hockings K, McGrew WC, Richmond BG, Matsuzawa T. 2012. Chimpanzee carrying behavior and the origins of human bipedality. Curr Biol 22:R180-R181.

Cashmore LA, Zakrzewski SR. 2013. Assessment of musculoskeletal stress marker development in the hand. Int J Osteoarchaeol 23: 334-347.

Cinamon U. 2009. The growth rate and size of the mastoid air cell system and mastoid bone: a review and reference. Eur Arch Otorhinolaryngol 266:781-786.

Coren S, Porac C, Duncan P. 1981. Lateral preference behaviors in preschool children and young adults. Child Dev 52:443-450.

Cowgill LW. 2007. Humeral torsion revisited: a functional and ontogentic model for population variation. Am J Phys Anthropol 134:472-480.

D'Août K, Vereecke E, Schoonaert K, Clercq Van Elsacker DD, Aerts LP. 2004. Locomotion in bonobos (Pan paniscus): differences and similarities between bipedal and quadrupedal terrestrial walking, and a comparison with other locomotor modes. J Anat 204:353-361.
Dedieu P, Zanone P-G. 2012. Effects of gait pattern and arm swing on intergirdle coordination. Hum Mov Sci 31:660-671.

Dempster WT. 1961. Free-body diagrams as an approach to the mechanics of human posture and motion. In: Evans FG, editor. Biomechanical studies of the musculo-skeletal system. Springfield, IL: Charles C. Thomas. p 81-135.

Doran DM. 1993. Sex differences in adult chimpanzee positional behavior: the influence of body size on locomotion and posture. Am J Phys Anthropol 91:99-115.

Fatah EEA, Shirley NR, Mahfouz MR, Auerbach BM. 2012. A three-dimensional analysis of bilateral directional asymmetry in the human clavicle. Am J Phys Anthropol 149:547-559.

Gans C. 1974. Biomechanics: an approach to vertebrate biology. Philadelphia, PA: J.B. Lippincott Company.

Gilbert AN, Wysocki CJ. 1992. Hand preference and age in the United States. Neuropsychologia 30:601-608.

Ginsburg CM, Rudoy R, Nelson JD. 1980. Acute mastoiditis in infants and children. Clin Pediatr 19:549-553.

Griffiths RI. 1991. Shortening of muscle fibres during stretch of the active cat medial gastrocnemius muscle: the role of tendon compliance. J Physiol 436:219-236.

Herring SW, Rafferty KL, Liu ZJ, Marshall CD. 2001. Jaw muscles and the skull in mammals: the biomechanics of mastication. Comp Biochem Phys A 131:207-219.

Homberger DG. 1986. The lingual apparatus of the African Grey Parrot, Psittacus erithacus Linné, (Aves: Psittacidae): description and theoretical mechanical analysis. Ornithol Monogr 39:1-233.

Homberger DG. 1988. Models and tests in functional morphology: the significance of description and integration. Am Zool 28:217-229.

Hooton EA. 1946. Up from the ape. Revised edition. New York, NY: The MacMillan Co.

Jolly CJ. 1970. The seed-eaters: a new model of hominid differentiation based on a baboon analogy. Man 5:5-26.

Keen M. 1993. Early development and attainment of normal mature gait. J Prosthet Orthot 5:35-38.

Kendall FP, McCreary EK, Provance PG, Rodgers MM, Romani WA. 2005. Muscles: testing and function. 5th ed. Baltimore, MD: Lippincott Williams \& Wilkins.

Krahl VE. 1976. The phylogeny and ontogeny of humeral torsion. Am J Phys Anthropol 45:595-600.

Krantz GS. 1963. The functional significance of the mastoid process in man. Am J Phys Anthropol 21:591-593.

Ledebt A. 2000. Changes in arm posture during the early acquisition of walking. Infant Behav Dev 23:79-89.

LeMay M. 1977. Asymmetries of the skull and handedness: phrenology revisited. J Neurol Sci 32:243-253.

Loeb GE, Gans C. 1986. Electromyography for experimentalists. Chicago, IL: The University of Chicago Press.

Lovejoy CO. 1988. Evolution of human walking. Sci Am 259:118-125.

Luntz M, Brodsky A, Nusem S, Kronenberg J, Keren G, Migirov L, Cohen D, Zohar S, Shapira A, Ophir D, Fishman G, Rosen G, Kisilevsky V, Magamse I, Zaaroura S, Joachims HZ, Goldenberg D. 2001. Acute mastoiditis-the antibiotic era: a multicenter study. Inter J Pediatr Otorhi 57:1-9.

Mays S, Steele J, Ford M. 1999. Directional asymmetry in the human clavicle. Int J Osteoarchaeol 9:18-28.

McBirney A, Cook S. 2009. The philosophy of zoology before Darwin: a translated and annotated version of the original French text by Edmond Perrier. Rotterdam, Netherlands: Springer Netherlands.

Meyns P, Bruijns SM, Duysens J. 2013. The how and why of arm swing during human walking. Gait Posture 28:555-562.

Michaelson P, Michaelson M, Jaric S, Latash ML, Sjölander P, Djupsjöbacka M. 2003. Vertical posture and head stability in patients with chronic neck pain. J Rehabil Med 35:229-235.

Moore KL, Dalley AF, Agur AMR. 2010. Clinically oriented anatomy. 6th ed. Baltimore, MD: Lippincott Williams \& Wilkins.

Moore-Jansen PM, Ousley SD, Jantz RL. 1994. Data collection procedures for forensic skeletal material. Knoxville, TN: The University of Tennessee Forensic Anthropology Series.

Murachovsky J, Ikemoto RY, Nascimento LGP, Bueno RS, Strose E, Almeida LH. 2010. Does the presence of proximal humerus 
growth plate changes in young baseball pitchers happen only in symptomatic athletes? An X-ray evaluation of 21 young baseball pitchers. Br J Sports Med 44:90-94.

Nissan J, Gross MD, Shifman A, Tzadok L, Assif D. 2004. Chewing side preference as a type of hemispheric laterality. J Oral Rehabil 31:412-416.

Osborn ML 2013. The Shoulder suspension of bipedal humans and the head suspension of quadrupedal cats: a reconstruction of macroevolutionary changes of complex systems based on natural experiments, comparative anatomy, and biomechanical analyses of extant organisms. Ph.D. dissertation, Louisiana State University, Dept. of Biological Sciences. Available at: http://etd. lsu.edu/docs/available/etd-04112013-203731/

Parsons FG. 1916. On the proportions and characteristics of the modern English clavicle. J Anat 51:71-93.

Perelle IB, Ehrman L. 1994. An international study of human handedness: the data. Behav Genet 24:217-227.

Peters M, Durding BM. 1979. Footedness of left- and right-handers. Am J Psychol 92:133-142.

Pieper H-G. 1998. Humeral torsion in the throwing arm of handball players. Am J Sports Med 26:247-253.

Pontzer H, Holloway JH, Raichlen DA, Lieberman DE. 2009. Control and function of arm swing in human walking and running. J Exp Biol 212:523-534.

Pozzo T, Levik Y, Berthoz A. 1995. Head and trunk movements in the frontal plane during complex dynamic equilibrium tasks in humans. Exp Brain Res 106:327-338.

Preuschoft H, Witte H. 1991. Biomechanical reasons for the evolution of hominid body shape. In: Coppens Y, Senut B, editors. Origin(s) of bipedalism in hominids. Paris, France: CNRS. p 59-77.

Preuschoft H. 2004. Mechanisms for the acquisition of habitual bipedality: are there biomechanical reasons for the acquisition of upright bipedal posture? J Anat 204:363-384.

Preuschoft H, Hohn B, Scherf H, Schmidt M, Krause C, Witzel U. 2010. Functional analysis of the primate shoulder. Int J Primatol 31:301-320

Rhodes JA. 2006. Adaptations to humeral torsion in medieval Britain. Am J Phys Anthropol 130:160-166.

Rose MD. 1976. Bipedal behavior of olive baboons (Papio anubis) and its relevance to an understanding of the evolution of human bipedalism. Am J Phys Anthropol 44:247-262.

Roux W. 1881. Der Kampf der Theile im Organismus. Leipzig, Germany: Wilhelm Engelmann.

Ruff CB. 2005. Mechanical determinants of bone form: insights from skeletal remains. J Musculoskelet Neuronal Interact 5: 202-212.

Sanchis-Moysi J, Idoate F, Serrano-Sanchez JA, Dorado C, Calbet JAL. 2012. Muscle hypertrophy in prepubescent tennis players: a segmentation MRI study. PLoS One 7:1-7.

Schlecht SH. 2012. Understanding entheses: bridging the gap between clinical and anthropological perspectives. Anat Rec 295: 1239-1251.
Schultz AH. 1937. Proportions, variability and asymmetries of the long bones of the limbs and the clavicles in man and apes. Hum Biol 9:281-328.

Schmid P, ChurchillsE, Nalla S, Weissen E, Carlson KJ, de Ruiter DJ, Berger LR. 2013. Mosaic morphology in the thorax of Australopithecus sediba. Science 340:1234598-1-1234598-5-

Sládek V, Berner M, Sosna D, Sailer R. 2007. Human manipulative behavior in the central European late Eneolithic and early Bronze age: humeral bilateral asymmetry. Am J Phys Anthropol 133:669-681.

Steele J, Mays S. 2005. Handedness and directional asymmetry in the long bones of the human upper limb. Int J Osteoarchaeol 5: 39-49.

Stephenson JL, De Serres SJ, Lamontagne A. 2010. The effect of arm movements on the lower limb during gait after stroke. Gait Posture 31:109-115.

Strother GK. 1977. Physics with application in life sciences. Boston, MA: Houghton Mifflin Company.

Tobias PV. 1992. The upright head in hominid evolution. In: Berthoz A, Graf W, Vidal PP, editors. The head-neck sensory motor system. New York, NY: Oxford University Press. p 5-13.

Trevathan WR. 1988. Fetal emergence patterns in evolutionary perspective. Am Anthropol 90:674-681.

Trinkaus E, Churchill SE, Ruff CB. 1994. Postcranial robusticity in Homo. II: humeral bilateral asymmetry and bone plasticity. Am J Phys Anthropol 93:1-34.

Videan EN, McGrew WC. 2002. Bipedality in chimpanzee (Pan troglodytes) and bonobo (Pan paniscus): testing hypotheses on the evolution of bipedalism. Am J Phys Anthopol 118:184-190.

Virchow R. 1858. Knochenwachsthum und Schädelformen, mit besonderer Rücksicht auf Cretinismus. Virchows Arch 13: 323-357.

Volpato V, Macchiarelli R, Guatelli-Steinberg D, Fiore I, Bondioli L, Frayer DW. 2012. Hand to mouth in a Neandertal: righthandedness in Regourdou1. PLoS One 7:1-6.

Ward CV. 2002. Interpreting the posture and locomotion of Australopithecus afarensis: where do we stand? Yearb Phys Anthropol 119:185-215.

Weiss E. 2003. Understanding muscle markers: aggregation and construct validity. Am J Phys Anthropol 121:230-240.

White TD. 2000. Human osteology. 2nd ed. New York, NY: Academic Press.

Wolff J. 1892. Das Gesetz der Transformation der Knochen. Berlin, Germany: August Hirschwald. [Reprinted 2010: pp. A1-A105 (G. Bergmann and G. Duda, eds.). Berlin, Germany: Julius Wolff Institut, Charité Universitätsmedizin.

Woo TL. 1931. On the asymmetry of the human skull. Biometrika 22:324-352.

Wyland DJ, Pill SG, Shanley E, Clark JC, Hawkins RJ, Noonan TJ, Kissenberth MJ, Thigpen CA. 2012. Bony adaptation of the proximal humerus and glenoid correlate within the throwing shoulder of professional baseball pitchers. Am J Sports Med 40: 1858-1862. 